\title{
A problemática da adesão na prevenção da anemia ferropriva e suplementação com sais de ferro no município de Viçosa (MG)
}

\author{
Problems of adherence to the program of prevention \\ of iron deficiency anemia and supplementation with iron salts \\ in the city of Viçosa, Minas Gerais, Brazil
}

\author{
Catarina Machado Azeredo ${ }^{1}$ \\ Rosângela Minardi Mitre Cotta ${ }^{2}$ \\ Luciana Saraiva da Silva ${ }^{3}$ \\ Sylvia do Carmo Castro Franceschini ${ }^{2}$ \\ Luciana Ferreira da Rocha Sant'Ana ${ }^{2}$ \\ Joel Alves Lamounier ${ }^{4}$
}

${ }^{1}$ Faculdade de Medicina, Universidade Federal de Uberlândia. Av. Pará 1720/ bl. $2 \mathrm{U}$, Umuarama. 38400-902 Uberlândia MG. catarina@famed.ufu.br ${ }^{2}$ Departamento de Nutrição e Saúde, Universidade Federal de Viçosa.

${ }^{3}$ Conselho de Ensino, Pesquisa e Extensão, Universidade Federal de Viçosa.

${ }^{4}$ Departamento de Pediatria, Faculdade de Medicina, Universidade Federal de Minas Gerais.

\begin{abstract}
The scope of this article is to analyze the understanding of mothers and persons responsible for infants taking ferrous sulfate supplement about anemia and its consequences, assessed by the level of adherence to supplementation. A prospective, qualitative and quantitative population study was conducted with non-anemic children not taking supplements to receive prophylactic supplementation with ferrous sulfate for six months. After six months, there was adherence to supplementation. Among the 133 children initially eligible for the study, 97 returned for the second evaluation. Of these, 4 had anemia during the follow-up and began treatment and 3 others were brought in by individuals who were unable to provide information on use of the supplement. High adherence was showed by $56.7 \%$ of children and low adherence by $43.3 \%$, while $23.3 \%$ had interrupted supplementation due to the lack of guidance and support of the health service. Mothers and persons responsible of the two groups (high and low adherence) manifested little knowledge about anemia, its prevention and health consequences for the child. More information regarding iron deficiency anemia, routine follow-up by professionals and evaluation of the perception of individuals involved with iron supplementation is necessary. Key words Iron deficiency anemia, Family health program, Knowledge, Dietary supplements, Adherence
\end{abstract}

Resumo Foi analisada a apreensão das mães/responsáveis por lactentes suplementados com sulfato ferroso, sobre a anemia e suas consequências, por grau de adesão à suplementação. Pesquisa populacional, prospectiva e quanti-qualitativa. Selecionou-se crianças não anêmicas e que não estivessem recebendo suplementação. As mães/responsáveis foram orientadas a administrarem a suplementação profilática de ferro por seis meses e a adesão foi avaliada após o período. Dentre as 133 crianças elegíveis inicialmente para a pesquisa, foi possível reavaliar 90 pares crianças/responsáveis e realizaram-se entrevistas semiestruturadas com os responsáveis. Das crianças avaliadas, 56,7\% apresentaram alta adesão e 43,3\% baixa, sendo que 23,3\% destas tinham interrompido a suplementação, sendo os motivos mais frequentes a ausência de orientação e apoio do serviço de saúde. Dentre as mães/responsáveis, um baixo percentual reconheceu o sulfato ferroso como forma de prevenção da anemia, e ambos os grupos demonstraram pouco conhecimento acerca da anemia, suas formas de prevenção e consequências à saúde da criança. Há necessidade de mais informação através de atividades de promoção e educação em saúde incluindo estratégias participativas, acompanhamento dos profissionais de saúde e avaliação da percepção dos indivíduos envolvidos na suplementação.

Palavras-chave Anemia ferropriva, Programa Saúde da Família, Conhecimento, Suplementos dietéticos, Adesão 


\section{Introdução}

A anemia ferropriva ainda figura como uma das principais deficiências nutricionais, especialmente nos países em desenvolvimento e nos grupos de gestantes e de lactentes ${ }^{1}$.

Apesar dos esforços de diversas organizações internacionais na elaboração de guias e políticas para o controle e a redução dessa carência na população infantil, as prevalências de anemia vêm se mantendo elevadas, e existe enorme dificuldade de combatê-la, com destaque para a baixa adesão à suplementação com sais de ferro ${ }^{2}$.

No intuito de prevenir a anemia nos grupos vulneráveis, o Ministério da Saúde do Brasil criou, em 2005, o Programa Nacional de Suplementação de Ferro (PNSF). Este programa vem sendo implementado nos diversos municípios brasileiros e consiste na suplementação profilática com xarope de sulfato ferroso para crianças entre 6 e 18 meses de idade, na dosagem semanal de 25 mg de ferro ${ }^{3}$.

Devido à natureza multifatorial dessa deficiência, se faz necessária uma abordagem integrada que identifique todos os fatores determinantes de sua continuidade e que impedem o controle efetivo da mesma ${ }^{1}$. Como um grave problema de saúde pública, a anemia tem sua origem em um contexto mais amplo, no qual a sua ocorrência está determinada não só pelos fatores biológicos, como também pelas condições socioeconômicas e culturais vigentes ${ }^{4}$. Mesmo quando os suplementos estão disponíveis e as mães são orientadas a suplementarem seus filhos, muitas vezes não administram na dosagem correta e por tempo suficiente para obter benefícios nos níveis de hemoglobina ${ }^{5}$.

Considerando que a saúde e a doença envolvem uma complexa interação entre os aspectos físicos, psicológicos, sociais e ambientais da condição humana e de atribuições de significados, qualquer ação de tratamento, de prevenção ou de planejamento (em saúde) deveria, além de incluir o conhecimento técnico, estar atenta aos valores, atitudes e crenças dos grupos a quem essa ação se dirige ${ }^{6}$.

Nesse sentido, realizou-se o presente estudo no intuito de analisar a apreensão das mães/responsáveis por lactentes suplementados com sulfato ferroso em dosagem profilática, sobre a anemia e suas consequências, comparando-as ao grau de adesão à suplementação.

\section{Metodologia}

\section{Área do Estudo}

A pesquisa foi realizada no município de $\mathrm{Vi}$ çosa (MG), com população estimada, em 2007, de 76.081 habitantes ${ }^{7}$.

O Programa Saúde da Família (PSF) oferece cobertura a aproximadamente $56 \%$ da população total residente no município de Viçosa, e é composto por 13 Equipes de Saúde da Família (ESF), localizadas estrategicamente nas áreas socioeconomicamente mais vulneráveis. Todas as ESF contam com a equipe de saúde mínima recomendada pelo Ministério da Saúde, sendo que seis possuem ainda dentista, auxiliar de consultório dentário e nutricionista.

\section{Sujeitos}

$\mathrm{Na}$ época do estudo existiam 1.027 crianças na faixa etária entre 6 e 18 meses, das quais 560 eram atendidas pelas 13 ESF e as demais se dividiam entre convênios, particulares e atendimentos no Centro de Saúde do município. Compuseram o grupo estudado as crianças entre 6 e 18 meses de idade atendidas pelas ESF do Município de Viçosa e seus responsáveis que concordaram em participar do estudo.

\section{Desenho do Estudo}

Estudo populacional, prospectivo, de abordagem quanti-qualitativa. A coleta de dados ocorreu em dois momentos: (1) no período de agosto a outubro de 2007; e (2) de fevereiro a abril de 2008.

O processo de captação das mães e crianças avaliadas ocorreu por meio de convite, entregue nos domicílios pelos Agentes Comunitários de Saúde (ACS), além de cartazes afixados nas Unidades Básicas de Saúde (UBS). As avaliações ocorreram em dias agendados em cada uma das 13 UBS.

Das 560 crianças e mães convidadas a participarem da pesquisa, 327 (58,4\%) compareceram na primeira etapa do estudo. Nesta etapa, aplicou-se questionário semiestruturado com informações socioeconômicas e biológicas e realizouse o teste de anemia, no qual a amostra de sangue foi coletada por pesquisadores devidamente treinados através da punção digital, no dedo anular ou no calcanhar no caso de crianças que não andavam. Foi coletada uma gota de sangue utilizando-se uma lanceta descartável. A dosagem da hemoglobina foi realizada por leitura direta no hemoglobinômetro portátil, marca Hemocue ${ }^{\circledR}$. 
As crianças não anêmicas (hemoglobina > 11g/ $\mathrm{dL})$ e não suplementadas anteriormente $(\mathrm{n}=$ 133) foram selecionadas para serem suplementadas profilaticamente com o sulfato ferroso proposto pelo Ministério da Saúde 3 . A estratégia adotada por este consiste na administração semanal de $5 \mathrm{ml}$ de xarope de sulfato ferroso, contendo 25mg de ferro. Nesta ocasião, foi entregue pelos profissionais das Unidades Básicas de Saúde um frasco do xarope de sulfato ferroso aos responsáveis e aplicado questionário semiestruturado com informações socioeconômicas e biológicas dos lactentes e família. Foi entregue aos participantes a quantidade de xarope suficiente para três meses de suplementação e, após esse período, as mães foram orientadas pelos profissionais de saúde a retornarem aos PSF para receber novo frasco com a quantidade necessária para a suplementação por mais três meses, conforme norma do programa. A quantidade de xarope necessária para as crianças suplementadas esteve disponível nas UBS.

Após 6 meses do início da suplementação profilática, os responsáveis foram convidados a comparecerem às UBS com as crianças para reavaliação. Nesse momento, compareceram 97 pares crianças/responsáveis (72,9\% das crianças em suplementação profilática). Realizou-se o teste da anemia por procedimentos idênticos ao da primeira etapa da pesquisa. As entrevistas aos pais/responsáveis foram realizadas por pesquisadores devidamente treinados, sendo gravadas após o consentimento dos entrevistados e transcritas pela mesma pessoa que entrevistou permitindo informações de forma fidedigna. Foi aplicado questionário semiestruturado, abordando tópicos importantes para o estudo, como o tempo de suplementação, a frequência de administração do xarope e a prática da suplementação. Cada entrevista durava aproximadamente 30 minutos e aconteceu na própria UBS em espaço reservado para tal procedimento, permitindo a privacidade dos sujeitos.

A entrevista semiestruturada trata-se de uma técnica que utiliza um roteiro com perguntas previamente formuladas para orientar a abordagem do tema de interesse, mantendo questões abertas para que o entrevistado possa se expor livremente sobre o tema estudado ${ }^{6}$.

\section{Análise dos dados}

Utilizou-se como referencial para a análise das entrevistas a temática, com recorte do texto em unidades comparáveis, sob a forma de cate- gorização, como método de compreensão dos fenômenos, que pode colaborar na reflexão geral sobre as condições de produção e apreensão ${ }^{6}$, com o objetivo de apreender o que as mães/responsáveis pensam sobre a anemia ferropriva. $\mathrm{O}$ discurso, desta forma, transcende a linguagem, e sua análise é um processo de identificação de sujeitos, de argumentação, de subjetivação e de construção da realidade, onde sentidos são revelados e determinados ideologicamente e-10 $^{8-}$

O método consiste em "um conjunto de técnicas de análises das comunicações visando obter por procedimentos sistemáticos e objetivos de descrição do conteúdo das mensagens, indicadores (quantitativos ou não) que permitam a inferência de conhecimentos relativos às condições de produção/recepção (variáveis inferidas) dessas mensagens", que compreendeu as seguintes etapas: (1) Pré-análise: objetiva operacionalizar e sistematizar as ideias presentes no depoimento - apreensão do todo. Nesta fase, retomam-se as hipóteses e os objetivos iniciais da pesquisa, reformulando-os frente ao que foi coletado, caso seja necessário; (2) Exploração do material: consiste em identificar nas falas as unidades de significado - codificação, transformação dos dados brutos para compreensão do depoimento - essencial para a fase posterior; (3) Tratamento dos resultados: visa agrupar as unidades de significado de acordo com sua semelhança; (4) inferência e interpretação: a partir do unidades de significação se propõem inferências e então se interpreta o fenômeno estudado com base nos dados analisados e no aparato teórico do pesquisador ${ }^{6,11}$.

Os dados quantitativos foram analisados utilizando-se o software SPSS for Windows, versão 15.0 e Epi Info versão 6.04.

De acordo com definição da World Health Organization $^{12}$, a adesão é representada pelo grau em que o comportamento de uma pessoa corresponde e concorda com as recomendações do profissional de saúde, no caso, representado pela ingestão do medicamento. Como não existe um padrão consensual sobre qual percentual de utilização da medicação constitui uma adesão adequada $^{13}$, para efeito deste estudo, foi avaliada por método indireto, de acordo com a quantidade de xarope utilizada no período, segundo informação fornecida pelas mães. No momento da reavaliação era questionado o número de frascos de xarope no período de 6 meses, em seguida apresentava-se um frasco de xarope do PNSF para que fosse mostrada a quantidade restante. Se a criança tivesse ingerido mais de $75 \%$ (1 1 $1 / 2$ 
frasco, $>90 \mathrm{~mL}$ ) da quantidade prevista, a adesão era classificada como alta, esse valor sugere ingestão do suplemento em pelo menos $75 \%$ das semanas previstas, sendo um fator modificador do impacto da intervenção; se tivesse ingerido menos era classificada como baixa adesão $0^{14}$. O método indireto de avaliação da adesão por meio de entrevistas, utilizado neste estudo, foi escolhido pelo baixo custo e pela fácil operacionalização, mas possui o viés da superestimativa da adesão, pois o indivíduo pode esconder do entrevistador a forma como realizou o tratamento na realidade e a quantidade de medicamento administrada. Entretanto, essa limitação é discutível para qualquer tipo de levantamento, pelo constrangimento do entrevistado, sua vontade de responder o que seria correto pela pressão, mesmo que não intencional, da inquisição.

O trabalho foi aprovado pelo Comitê de Ética em Pesquisa com Seres Humanos da Universidade Federal de Viçosa.

\section{Resultados}

\section{Caracterização do grupo de estudo}

Dentre as 133 crianças elegíveis inicialmente para a pesquisa (não anêmicas e não suplementadas anteriormente), 97 compareceram à reavaliação. Destas, 4 tiveram anemia durante o seguimento, passando a receber tratamento e outras 3 foram levadas por pessoas que não souberam informar sobre a utilização do suplemento. Assim, compôs o grupo de estudo 90 pares crianças/responsáveis (representando 16,1\% do total de crianças/responsáveis adscritas pelas ESF e $67,7 \%$ das crianças elegíveis inicialmente).

Os lactentes apresentaram inicialmente mediana de idade de 11 meses (mínimo de 6 e máximo de 18 meses). A maioria destes era do gênero feminino $(53,3 \%, \mathrm{n}=48)$ e residia na zona urbana $(80,0 \%, n=72)$. A mediana de renda familiar foi equivalente a um salário-mínimo vigente em 2007 ( $\mathrm{R} \$ 380,00$ ), variando de 0,3 a 3,9 salários. Já a mediana da renda per capita foi inferior a 0,5 salário-mínimo, variando de 0,06 a 0,9 salário.

Quanto à escolaridade materna, a maioria $(43,3 \%)$ possuía o ensino fundamental incompleto, sendo que a mediana de anos de estudo foi igual a 8 (mínimo: 1 ano; máximo: 11 anos). Do total de mães, $11,1 \%$ eram adolescentes; a mediana de idade materna foi de 26 anos, variando entre 16 e 55 anos; a maioria das mães possuía companheiro $(82,2 \%, \mathrm{n}=74)$; quanto à ocupa- ção, as mães entrevistadas, em sua maioria, eram donas de casa $(71,1 \%)$.

Comparando as características biológicas, socioeconômicas e de saúde entre os lactentes que constituíram as perdas e os que completaram o estudo, os achados minimizam a possibilidade de que os resultados finais tivessem sido influenciados pelo viés das perdas diferenciadas e de certa forma asseguram que as crianças que completaram o estudo são representativas do total de crianças inicialmente avaliadas, exceto pela média de idade $(p=0,044)$. A possível limitação relatada acima, não invalida ou diminui a relevância dos resultados encontrados.

\section{Adesão à suplementação}

Após seis meses de suplementação com sulfato ferroso, observou-se que $56,7 \%(\mathrm{n}=51)$ das crianças apresentaram alta adesão e 43,3\% ( $\mathrm{n}=39$ ) baixa, sendo que deste último grupo 21 crianças haviam interrompido a utilização do suplemento por mais de um mês.

\section{Apreensão das mães/responsáveis sobre a anemia ferropriva}

A anemia ferropriva transcende o aspecto biológico, abrangendo dimensões sociais e culturais do indivíduo ${ }^{4}$. Enquanto os hábitos culturais se refletem nas práticas alimentares, determinando a escolha dos alimentos a serem consumidos, e em última análise na presença da doença, a própria adesão a determinado tratamento ou prevenção, se relaciona ao sentido que a anemia tem para os indivíduos, ou seja, para o senso comum.

É importante salientar que $25,6 \%(\mathrm{n}=10)$ das mães/responsáveis por crianças com baixa adesão e $23,5 \%(n=12)$ com alta adesão não souberam emitir qualquer opinião sobre o que seria a anemia. Dentre as mães/responsáveis que responderam, a anemia apresentou significados que podem ser visualizados na Tabela 1 .

Analisando a percepção materna sobre o conceito de anemia (Tabela 1), segundo o conceito de análise do discurso, observa-se semelhança entre indivíduos cujos filhos tiveram alta ou baixa adesão à suplementação, variando, entretanto, o percentual de citação nos dois grupos.

Um fato importante a ser salientado, resultado da análise dos depoimentos das mães/responsáveis por crianças com baixa adesão, refere-se ao sentimento de incapacidade frente ao controle da anemia. Esse sentimento esteve aliado à ideia 
Tabela 1. Representações sociais acerca da anemia, por grau de adesão à suplementação com sulfato ferroso, dos responsáveis por crianças menores de dois anos, município de Viçosa, MG, Brasil (2008).

\begin{tabular}{|c|c|c|}
\hline Categorias & Baixa adesão $(n=29)$ & Alta adesão $(n=49)$ \\
\hline $\begin{array}{l}\text { Relacionam com os } \\
\text { sinais clínicos da } \\
\text { anemia }\end{array}$ & $\begin{array}{l}(\mathrm{n}=9) 23,1 \% \text {... } \\
\text { é a criança num responder, aos poucos } \\
\text { fica pálida, parada, quieta, não se } \\
\text { alimenta direito...é menino que não } \\
\text { come, fica indisposto, não brinca. }\end{array}$ & $\begin{array}{l}(\mathrm{n}=21) 41,2 \% \\
\text { é aquela criança que fica desanimada, não } \\
\text { qué brincá. ... eu acho que a criança fica } \\
\text { menos resistente. }\end{array}$ \\
\hline $\begin{array}{l}\text { Relacionam com as } \\
\text { causas da anemia }\end{array}$ & $\begin{array}{l}(\mathrm{n}=8) 20,5 \% \text {... } \\
\text { é porque as pessoas não come } \\
\text { verdura, nem legume, igual feijão. ... } \\
\text { porque eles falam que quem tá com } \\
\text { anemia, tá com verme. }\end{array}$ & $\begin{array}{l}(\mathrm{n}=6) 11,8 \% \\
\text {... é falta de dar o fígado de boi, alguma } \\
\text { coisa assim, feijão... Eu acho que anemia é } \\
\text { verme, não é não? }\end{array}$ \\
\hline Deficiência de ferro & $\begin{array}{l}(\mathrm{n}=8) 20,5 \% \\
\text { é falta de ferro, eu acho que é isso. } \\
\text { Falta de ferro no sangue. }\end{array}$ & $\begin{array}{l}(\mathrm{n}=8) 15,7 \% \\
\text {...é assim é uma carência de ferro, né que a } \\
\text { pessoa tem... né? sei lá, falta de ferro no } \\
\text { sangue. Falta de ferro no sangue. }\end{array}$ \\
\hline Sangue Fraco & $\begin{array}{l}(\mathrm{n}=4) 10,3 \% \\
\text {...é sangue fraco que eles fala } \\
\text { [risos]....num sei se é sangue que vira } \\
\text { água.. }\end{array}$ & $\begin{array}{l}\text { (n=4) } 7,8 \% \\
\text { Ah... eu acho que é água no sangue né?...é } \\
\text { alguma coisa no sangue que fica fraco... }\end{array}$ \\
\hline
\end{tabular}

Baixa adesão: ingestão de menos de $75 \%\left(1 \frac{1}{2}\right.$ frasco, $\left.<90 \mathrm{~mL}\right)$ da quantidade prevista de xarope. Alta adesão: ingestão de mais de $75 \%$ $\left(1 \frac{1}{2}\right.$ frasco, $\left.>90 \mathrm{~mL}\right)$ da quantidade prevista de xarope.

de que é uma enfermidade comum, hereditária e natural e, portanto, de difícil controle pelo ser humano, apontando para certo conformismo, o que pode justificar a falta de adesão ao tratamento, conforme ilustram os relatos abaixo:

Ah... a anemia é genético, porque duas pessoas da família minha faleceu, né!

...eu penso o seguinte: todo mundo tem, alguns já tem ela controlada e outros deixam a doença agravar mais, mas a princípio a anemia é uma coisa comum no ser humano...

\section{Prevenção da anemia ferropriva}

Sobre a prevenção da anemia, verificou-se que maior percentual de mães/responsáveis por crianças com baixa adesão $(20,5 \%, \mathrm{n}=8)$ não soube relatar nenhuma atitude de prevenção, quando comparado àquelas com alta adesão $(5,9 \%, \mathrm{n}$ $=3)$. Dentre os entrevistados que responderam sobre a prevenção da anemia, nos grupos com alta e baixa adesão, $79,5 \%$ e $94,1 \%$, respectivamente, mencionou pelo menos um modo de prevenir (Tabela 2).

Analisando a Tabela 2, observa-se que somente um pequeno percentual de responsáveis nos dois grupos reconheceu o sulfato ferroso como sendo uma forma de prevenção, o que certamente está associado aos problemas de adesão encontrados.

\section{Consequências da anemia à saúde da criança}

As consequências da anemia para a saúde dos lactentes são inúmeras e o conhecimento da gravidade das mesmas pelas mães pode servir de estímulo à utilização correta do suplemento. Nessa perspectiva, os resultados do presente estudo, no que se refere aos prejuízos ocasionados pela anemia, são preocupantes. Observou-se que boa parte das mães/responsáveis não soube citar nenhuma consequência para a saúde de seus filhos, sendo que no grupo de alta e no de baixa adesão essa categoria foi de $27,5 \%(\mathrm{n}=14)$ e $38,5 \%(n=15)$, respectivamente.

As representações do grupo de mães/responsáveis que relataram consequências negativas da anemia estão dispostas na Tabela 3. Analisandoa, um ponto que chama atenção é a referência à "anemia passada", que segundo $10,3 \%$ e $23,5 \%$ dos responsáveis no grupo com baixa adesão e no com alta, respectivamente, diz respeito ao agravamento da anemia ferropriva, levando à 
Tabela 2. Formas de prevenção da anemia, por grau de adesão à suplementação com sulfato ferroso, segundo as mães/responsáveis por crianças menores de dois anos, município de Viçosa, MG, Brasil (2008).

\begin{tabular}{|c|c|c|}
\hline Categorias & Baixa adesão $(\mathbf{n}=31)$ & Alta adesão $(n=48)$ \\
\hline $\begin{array}{l}\text { Alimentos fonte } \\
\text { de ferro }\end{array}$ & $\begin{array}{l}(\mathrm{n}=16) 41,1 \% \\
\text { Dando verduras, igual a taioba, couve, } \\
\text { brócolis... feijão, carne, fígado de boi, } \\
\text { bastante feijão, beterraba. }\end{array}$ & $\begin{array}{l}(\mathrm{n}=33) 64,7 \% \\
\text { Dar as coisas fortes, né? que tem vitamina, } \\
\text { fígado de boi, beterraba, carne, suco de } \\
\text { laranja, limão, acerola, folhas verdes. }\end{array}$ \\
\hline $\begin{array}{l}\text { Alimentação } \\
\text { saudável }\end{array}$ & $\begin{array}{l}(\mathrm{n}=10) 25,6 \% \\
\text { É comer bastante legumes, fruta, é } \\
\text { alimentar na hora certa, suco, bastante } \\
\text { suco, água. }\end{array}$ & $\begin{array}{l}(\mathrm{n}=8) 15,7 \% \\
\text { Comer muita verdura, legumes, frutas, } \\
\text { alimentos que contem muita vitamina. }\end{array}$ \\
\hline Sulfato ferroso & $\begin{array}{l}(\mathrm{n}=2) 5,1 \% \\
\text { eu sei assim é tomar sulfato ferroso. }\end{array}$ & $\begin{array}{l}(\mathrm{n}=4) 7,8 \% \\
\text { a gente acaba prevenindo [a anemia] com o } \\
\text { xarope [de sulfato ferroso]. }\end{array}$ \\
\hline $\begin{array}{l}\text { Evitar inibidores da } \\
\text { absorção de ferro }\end{array}$ & $\begin{array}{l}(\mathrm{n}=2) 5,1 \% \\
\text { [não pode] dar comida e dá ela leite... } \\
\text { dá mingau em cima, mamá no peito. }\end{array}$ & $\begin{array}{l}(\mathrm{n}=2) 3,9 \% \\
\text { não dá mamadeira antes e depois de } \\
\text { acabar de comer, isso eu sei, não pode dá } \\
\text { café, esses trem assim, refrigerante. }\end{array}$ \\
\hline Higiene & $\begin{array}{l}\text { ( } \mathrm{n}=1) 2,6 \% \\
\text { Ah, acho que lavar os legume bem, lavar } \\
\text { a mão bem antes de almoçar, se for comer } \\
\text { algum biscoito durante o dia lavar a } \\
\text { mão, eu acho que é isso, não deixar comer } \\
\text { as coisa do chão. }\end{array}$ & $\begin{array}{l}(\mathrm{n}=1) 2,0 \% \\
\text { não deixar brincar assim no meio da terra, } \\
\text { no meio da areia, porque brinca vai e coloca } \\
\text { a mão na boca. }\end{array}$ \\
\hline
\end{tabular}

Baixa adesão: ingestão de menos de $75 \%\left(1 \frac{1}{2} \mathrm{frasco},<90 \mathrm{~mL}\right.$ ) da quantidade prevista de xarope. Alta adesão: ingestão de mais de $75 \%\left(1 \frac{1}{2}\right.$ frasco, $\left.>90 \mathrm{~mL}\right)$ da quantidade prevista de xarope.

Tabela 3. Consequências da anemia à saúde, por grau de adesão à suplementação com sulfato ferroso, segundo as mães/responsáveis por crianças menores de dois anos, município de Viçosa, MG, Brasil (2007).

\begin{tabular}{|c|c|c|}
\hline Categorias & Baixa adesão $(n=24)$ & Alta adesão $(n=37)$ \\
\hline Letalidade & $\begin{array}{l}(\mathrm{n}=4) 10,3 \% \\
\text { Meu irmão deu anemia, anemia tava } \\
\text { alta, ai não cuidou, virou água no } \\
\text { sangue, ai morreu com } 29 \text { anos... } \\
\text { Anemia eles falam que anemia mata. } \\
\text { Deus me livre! }\end{array}$ & $\begin{array}{l}\text { ( } \mathrm{n}=12) 23,5 \% \\
\text {... anemia passada mata, talvez porque não } \\
\text { faz tratamento. É a mesma coisa de } \\
\text { leucemia. Nosso Deus! Eu morro de medo! Já } \\
\text { teve gente na família né, que teve isso, aí } \\
\text { chegou até a falecer porque virou leucemia... }\end{array}$ \\
\hline $\begin{array}{l}\text { Consequências } \\
\text { funcionais }\end{array}$ & $\begin{array}{l}(\mathrm{n}=8) 20,5 \% \ldots \\
\text { dá mais trabalho pra gente né? Adoece } \\
\text { mais. ... cêis fala que atrapalha o } \\
\text { crescimento, quando for pra escola não } \\
\text { consegue se desenvolver }\end{array}$ & $\begin{array}{l}(\mathrm{n}=7) 13,7 \% \\
\text {... Ela fica doente com mais facilidade... } \\
\text { abaixa o sistema imunológico delas } \\
\text { né?porque a criança que tem anemia que } \\
\text { não desenvolve direito não. }\end{array}$ \\
\hline Sinais Clínicos & $\begin{array}{l}(\mathrm{n}=12) 30,7 \% \ldots \\
\text { ela não come direito, é difícil costuma } \\
\text { voltar o alimento. fica uma criança } \\
\text { fraca, abatida }\end{array}$ & $\begin{array}{l}(\mathrm{n}=18) 35,3 \% \\
\text { É porque ela não se alimenta direito... não } \\
\text { fica com aquela vontade de brincar, fica } \\
\text { queto, quando ta bem, num é assim? }\end{array}$ \\
\hline
\end{tabular}

Baixa adesão: ingestão de menos de $75 \%\left(1 \frac{1}{2}\right.$ frasco, $\left.<90 \mathrm{~mL}\right)$ da quantidade prevista de xarope. Alta adesão: ingestão de mais de $75 \%\left(1 \frac{1}{2}\right.$ frasco, $\left.>90 \mathrm{~mL}\right)$ da quantidade prevista de xarope. 
leucemia. Tal representação se apresentou como forte fator cultural entre os entrevistados, remetendo à ideia de letalidade.

\section{Dificuldades na Suplementação}

Quanto às dificuldades em administrar o xarope de sulfato ferroso para seus filhos, 51,3\% $(\mathrm{n}=20)$ das mães/responsáveis do grupo com baixa adesão e 52,9\% $(\mathrm{n}=27)$ daquelas do grupo com alta adesão, responderam que tiveram problemas. Fato importante é que, apesar dos dois grupos terem relatado dificuldades para administrar o xarope, o grupo com alta adesão foi capaz de contornar os problemas, não interrompendo a administração do sulfato ferroso aos seus filhos.

No presente estudo, uma das dificuldades relatadas pelos entrevistados para a continuidade da suplementação foi o esquecimento, sendo que $15,4 \%$ eram mães/responsáveis por crianças com baixa e 17,6\% com alta adesão. Entretanto, observou-se que o esquecimento das mães/responsáveis por crianças com alta adesão (AA) se referiu somente ao horário e dia de administração do xarope, oferecendo-o no dia seguinte ou no mesmo dia em outro horário, enquanto para aquelas do grupo com baixa adesão (BA) o intervalo de esquecimento era superior a uma semana, interferindo na dosagem oferecida à criança. Como pode ser observado nos depoimentos a seguir:

...tenho [dificuldade] de lembrar, mas só a hora que eu esqueço. Lembrar no mesmo dia, eu alembro... só a hora que eu esqueço de dá... (AA)

Tem vez que eu esqueço, eu dô na segunda, ai eu dô noutro dia da semana, sexta, mas nunca deixo de dar não. (AA)

...eu esqueço, sabe! É uma vez só por semana, né, uma vez por semana antes do almoço, né, eu esqueço... várias semanas eu esqueço de dar. (BA)

... ela toma uma vez por semana, só que eu sou danada pra esquecer. Se fosse todo dia eu não esquecia. Tem vez que ela fica a semana toda sem tomar. (BA)

Outra dificuldade relatada pelos grupos entrevistados foi a rejeição ao xarope por $35,3 \%$ das crianças com alta adesão e 25,6\% com baixa. Contudo, observou-se que a atitude das mães/ responsáveis frente à rejeição da criança ao suplemento diferiu entre os grupos com alta ou baixa adesão.

Assim, apesar do percentual de rejeição ter sido maior entre as mães/responsáveis por crianças com alta adesão, a reação de 77,8\% destas frente à rejeição foi a insistência, fato que só ocorreu com $40 \%$ das mães/responsáveis por crianças com baixa adesão. A insistência pode ser visualizada pelas falas que se seguem:

Tenho [dificuldade] demais da conta, [porque] ele cospe. Ai vai, eu dou de novo. (AA)

Normalmente dou com suco, mas... eu dou mesmo é com seringa, ai dá pra ele engolir mais rápido, né. (AA)

Também os efeitos adversos ao suplemento foram citados como dificuldade para a continuidade da suplementação - somente pelas mães/ responsáveis com baixa adesão (10,3\%). Não obstante, quando questionados sobre a presença de efeitos adversos ao sulfato ferroso (vômito, diarreia, dente manchado, constipação e cólica), observou-se que 43,6\% das mães/responsáveis com baixa adesão e 19,6\% com alta adesão relataram a presença destas manifestações em seus filhos.

\section{Interrupção precoce da suplementação}

As mães/responsáveis que interromperam a administração do sulfato ferroso para as crianças antes do período de 6 meses $(n=21,23,3 \%)$ foram questionadas sobre as razões para esse comportamento. A síntese dos motivos relatados encontra-se na Figura 1.

\section{Discussão}

De acordo com a $\mathrm{WHO}^{12}$, a adesão a determinado medicamento possui cinco dimensões compostas por fatores relacionados: à doença, ao tratamento, às condições socioeconômicas, ao sistema e equipe de saúde e ao paciente.

Nesse sentido, destacam-se algumas considerações sobre o contexto estudado: relacionada à doença existe grande dificuldade de manter a motivação para ingerir o suplemento por indivíduos aparentemente saudáveis ${ }^{5}$, já que a anemia, na maioria dos casos, não é uma doença que possui sintomas graves. Especificamente no presente estudo, o grupo avaliado era composto por não anêmicos, tratando-se de uma atitude preventiva.

Em relação ao tratamento/profilaxia, destaca-se que além dos efeitos adversos causados pelo suplemento, a suplementação com ferro só é efetiva por períodos relativamente longos, de forma que o uso do medicamento pode ser interrompido muito antes que a suplementação tenha um impacto positivo ${ }^{15}$. No contexto estudado, cerca de $30 \%$ das crianças apresentou efeitos 


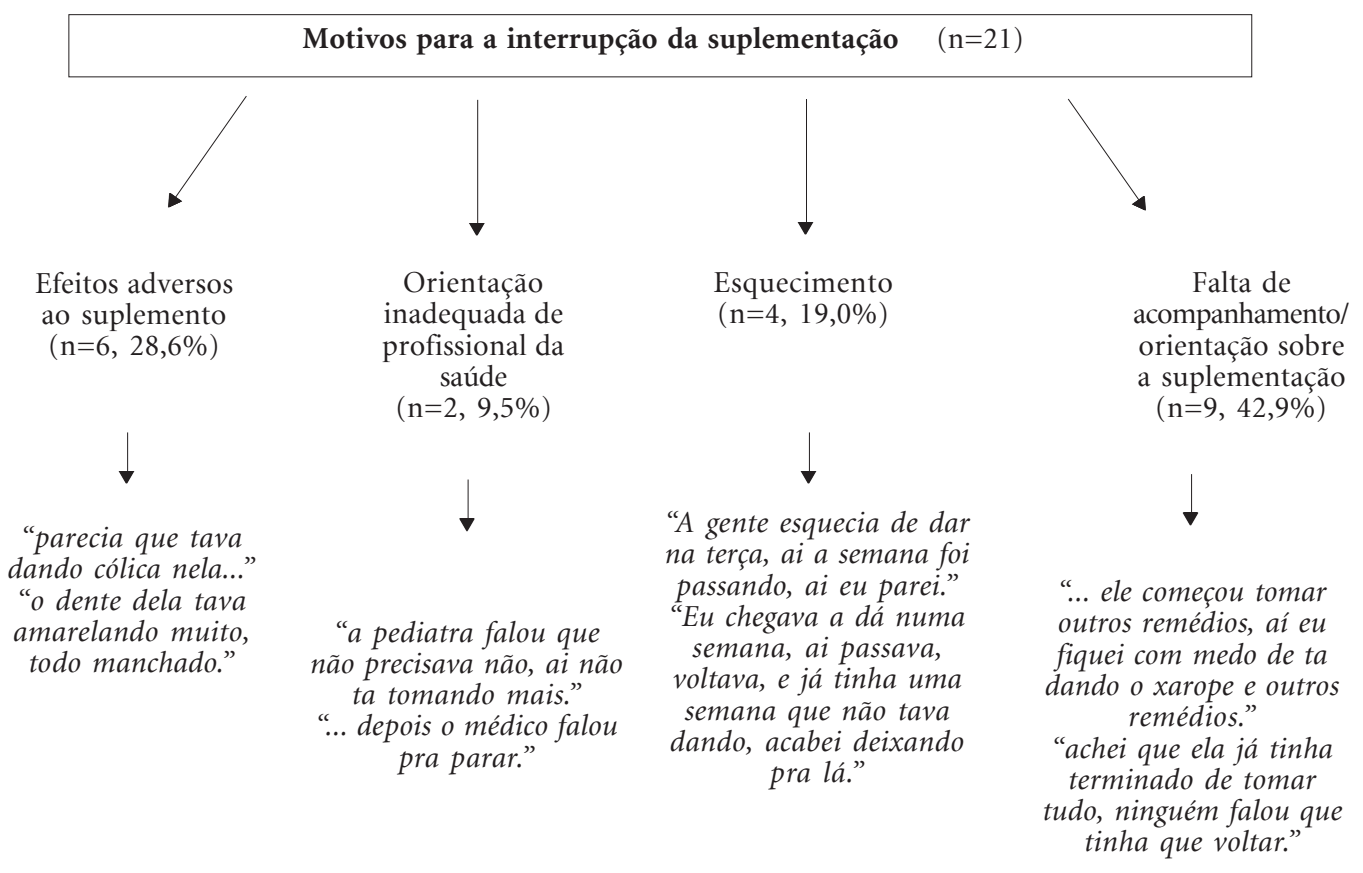

Figura 1. Razões para a interrupção da suplementação com sulfato ferroso semanal, segundo mães/ responsáveis por crianças menores de dois anos, município de Viçosa, MG, Brasil (2008).

adversos ao xarope e o período de suplementação foi de seis meses. Deve-se considerar ainda, que a cultura do uso de medicamento está associada ao tratamento de determinada doença e não à profilaxia, como ocorreu neste estudo, o que pode ter contribuído ainda mais para a baixa adesão encontrada.

Outro ponto é que, piores condições socioeconômicas se relacionam diretamente à baixa adesão, e embora a anemia seja uma deficiência que atinge a todas as classes sociais, aquelas mais vulneráveis estão expostas a mais fatores de risco, apresentando maior prevalência ${ }^{16}$. Nesse sentido, as mães/crianças estudadas apresentaram baixa condição socioeconômica, vivendo em áreas de maior vulnerabilidade social, como baixa renda per capita e baixa escolaridade.

No que se refere aos fatores relacionados à equipe de saúde, como orientações, acompanhamento e vínculo com a comunidade, e ao paciente, tais como os conhecimentos e crenças, estes surgem como áreas determinantes ao incremento da adesão por serem alvo de ações complexas, porém com menor custo. Todas essas cinco dimensões descritas certamente influenciaram na baixa adesão observada neste estudo (56,7\%), entretanto, devido à sua grande importância, os dois últimos fatores serão discutidos mais especificamente.

Sobre o conceito de anemia, dentre as respostas obtidas, destacam-se ideias vagas e fragmentadas acerca da deficiência, tanto no grupo com alta quanto no com baixa adesão. No estudo de Teixeira-Palombo e Fujimori ${ }^{17}$, que avaliou o conhecimento de educadoras infantis de uma creche pública na cidade de São Paulo sobre anemia, os autores observaram a presença de conceitos equivocados ou incompletos - resultado semelhante ao encontrado no presente estudo.

Nessa perspectiva, Galloway et al. ${ }^{18}$, verificaram que a apreensão da anemia entre gestantes de oito países estava vinculada aos seus sintomas ao invés de seu nome clínico ou doença específica, o que também se aproximou dos achados relatados no presente estudo.

Outro ponto importante foi o conformismo com a deficiência, observado nas mães cujos filhos tiveram baixa adesão. Galloway et al. ${ }^{18}$ também encontraram certo conformismo, exemplificado pela frase: "Nós todos temos um pouco de anemia, mas algumas pessoas têm mais gra- 
ve, anemia que penetra nos ossos e é difícil de curar". Ressalta-se que a falta de informação pode estar presente tanto no atendimento à mulher durante o pré-natal, quanto naquele durante o pós-parto e puericultura.

A concepção da anemia enquanto algo hereditário ou natural do ser humano, observada neste estudo, foi semelhante ao encontrado por Teixeira-Palombo e Fujimori ${ }^{17}$, e pode ter exercido influência negativa tanto na adoção de práticas alimentares que previnam esse agravo, quanto na administração do xarope, pois sendo hereditário nada poderia ser feito.

Com isso, pode-se inferir que o desconhecimento e a apreensão fragmentada do fenômeno anemia observados neste estudo contribuíram para a baixa adesão. Contudo, esse fato pode ser revertido por meio de ações de educação em saúde em estabelecimentos de ensino (escolas, creches) e de saúde (unidades de saúde, PSF). Estudo desenvolvido por Suárez ${ }^{19}$ vai ao encontro desta assertiva, pois constatou uma melhora evidente na quantidade e qualidade de conhecimento de gestantes sobre a anemia e sua prevenção a partir de uma simples intervenção educativa na comunidade.

Sobre a prevenção da anemia, a questão mais evidente foi o baixo percentual de mães/responsáveis que reconheceu o sulfato ferroso como uma forma de evitar a doença. Ressalta-se que os entrevistados administraram ou estavam administrando o sulfato ferroso às crianças no momento da pesquisa, o que aponta para o fato de que estes não internalizaram a importância do xarope para a prevenção. Há que se salientar, portanto, a necessidade de se pensar e implementar estratégias inovadoras de educação sanitária e promoção da saúde nas agendas das equipes do PSF, visando minimizar interferências entre o que é informado pelos profissionais de saúde e aquilo que é apreendido pelas mães/responsáveis, de modo a efetivar a sensibilização.

Em relação às consequências da anemia, chama atenção o fato de as mães acreditarem que "a anemia pode levar à leucemia”, o que evidencia o desconhecimento dos entrevistados frente à doença, uma vez que a leucemia é uma neoplasia maligna dos glóbulos brancos, que não possui relação com a anemia ferropriva ${ }^{20}$. Assim como no presente estudo, Teixeira-Palombo e Fujimori ${ }^{17}$ observaram a referência à anemia como "precursora" da leucemia ("anemia transforma-se em leucemia”).

Destaca-se que, no presente estudo, o principal fator para a interrupção precoce da suplementação foi a ausência de orientação, acompa- nhamento e apoio dos serviços de saúde, o que aponta para a importância estratégica dos profissionais da atenção primária na promoção da saúde e prevenção de agravos e enfermidades. De acordo com esses resultados, autores relatam que os principais fatores para a baixa adesão ao sulfato ferroso são: a ausência de capacitações, cooperação e motivação por parte de profissionais de saúde ${ }^{15}$ além da falta de maior vínculo entre estes e a comunidade ${ }^{12}$.

Conclui-se que a suplementação com sulfato ferroso demonstrou-se um fenômeno frequentemente negligenciado ou esquecido pelas mães e profissionais de saúde, pois as mães/responsáveis dos dois grupos (com alta e baixa adesão) demonstraram pouco conhecimento acerca da anemia, suas formas de prevenção e consequências à saúde da criança. Estudo sobre adesão à medicação em pediatria concluiu que o fato de os pais não compreenderem a importância de uma doença ou do uso do medicamento constitui forte entrave para a adesão ao mesmo ${ }^{21}$. Este fato foi confirmado por estudo realizado em Israel, que demonstrou que o conhecimento de mães de crianças entre 9 e 12 meses de idade, sobre a anemia, esteve relacionado de forma estatisticamente significante com a alta adesão (autorrelatada) e com baixa prevalência desta deficiência, controlando-se diversos fatores de confusão ${ }^{22}$.

Os discursos das mães/responsáveis apontam para a necessidade de implantação de estratégias de acompanhamento contínuo dessas crianças/mães pela equipe de saúde do PSF, já que somente a preconização da suplementação medicamentosa com sulfato ferroso não pode dar ao profissional a certeza de que a criança está realmente recebendo o suplemento ${ }^{23}$. Portanto, a adoção de uma rotina de suplementação profilática com ferro pelos profissionais de saúde deve envolver a padronização da dosagem e o monitoramento da adesão ${ }^{24}$, além de uma abordagem global do problema, visando à adoção de medidas que transcendem a visão isolada do tratamento da deficiência de ferro ${ }^{23}$.

Para aumentar a consciência das mães/responsáveis acerca da anemia e da necessidade da suplementação de ferro para a saúde de seus filhos, as atividades de promoção e educação em saúde devem incluir estratégias participativas. Além de considerar a percepção dos indivíduos envolvidos na suplementação tanto na formulação dos programas, quanto no monitoramento e na avaliação das estratégias adotadas, visando à efetividade da intervenção. 


\section{Colaboradores}

CM Azeredo, RMM Cotta, LS Silva, SCC Franceschini, LFR Sant'Ana e JA Lamounier participaram igualmente de todas as etapas de elaboração do artigo.

\section{Referências}

1. World Health Organization (WHO). Worldwide prevalence of anaemia 1993-2005. WHO Global Database on Anaemia. Geneva: WHO; 2008.

2. Batista Filho M, Souza AI, Bresani CC. Anemia como problema de saúde pública: uma realidade atual. Cien Saude Colet 2008; 13(6):1917-1922.

3. Brasil. Ministério da Saúde (MS). Secretaria de Atenção à Saúde. Departamento de Atenção Básica. Manual operacional do Programa Nacional de Suplementação de Ferro. Brasília: MS; 2005. (Série A. Normas e Manuais Técnicos).

4. Martins IS, Alvarenga AT, Siqueira AAF, Szarfac SC, Lima FD. As determinações biológica e social da doença: um estudo de anemia ferropriva. Rev Saude Publica 1987; 21(2):73-89.

5. Panamá. Ministerio de Salud (MS). Direccion General de Salud. Departamento de Nutricion. Fondo de las Naciones Unidas para la Infancia (UNICEF). Organización Panamericana de la Salud. Situación de deficiencia de hierro y anemia. Panamá: MS; 2006.

6. Minayo MCS. O desafio do conhecimento: Pesquisa Qualitativa em Saúde. São Paulo, Rio de Janeiro: Hucitec, Abrasco; 2006.

7. Instituto Brasileiro de Geografia e Estatística (IBGE). Dados Populacionais 2007. [acessado 2008 mar 04]. Disponível em: http://www.datasus.gov.br.

8. Monteiro SL, Piovesan AMW, Mohr D, Forlin CM, Martinez JZ, Franco Z. A análise do discurso e questões sobre a linguagem. Rev X 2006; 2:1-18.

9. Foucault M. Arqueologia do saber. 5a Edição. Rio de Janeiro: Forense Universitária, 1997.

10. Maingueneau D. Novas tendências em Análise do Discurso. 3a Edição. Campinas: Pontes, Unicamp; 1997.

11. Bardin L. Análise de conteúdo. Lisboa: Edições 70; 1977.

12. World Health Organization (WHO). Adherence to long-term therapies. Evidence for action. Geneva: WHO; 2003.

13. Osterberg L, Blaschke T. Drug Therapy: Adherente to medication. N Engl J Med 2005; 353(5):487-497.

14. Monteiro CA, Szarfac SC, Brunken GS, Gross R, Conde WL. A prescrição semanal de sulfato ferroso pode ser altamente efetiva para reduzir níveis endêmicos de anemia na infância. Rev Bras Epidemiol 2002; 5(1):71-83.

15. Galloway R, Mcguire J. Determinants of compliance with iron supplementation: supplies, side effects, or psychology? Soc Sci Med 1994; 39(3):381-390.
16. Capanema FD, Lamounier JA, Norton RC, Jácome AAA, Rodrigues DA, Coutinho RL, Tonidandel WC. Anemia Ferropriva na infância: novas estratégias de prevenção, intervenção e tratamento. Rev Médica de Minas Gerais 2003; 13(4 Supl. 2):30-34.

17. Teixeira-Palombo CN, Fujimori E. Conhecimentos e práticas de educadoras infantis sobre anemia. Rev Bras Saude Mater Infant 2006; 6(2):209-216.

18. Galloway R, Dusch E, Elder L, Achadi E, Grajeda R, Hurtado E, Favin M, Kanani S, Marsaban J, Meda N, Moore MK, Morison L, Raina N, Rajaratnam J, Stephen C. Women's perceptions of iron deficiency and anemia prevention and control in eight developing countries. Soc Sci Med 2002; 55(4):529-544.

19. Suárez YC. Conocimiento en gestantes sobre anemia y su prevención nutricional. Cesamo Paptalaya, municipio Ahuas. Departamento Gracias a Dios, Honduras. Revista Electrónica Temas de Investigación en Salud 2007; 1(2):1-17.

20. Instituto Nacional de Câncer (INCA). Leucemia. [acessado 2008 ago 31]. Disponível em: http://www. inca.gov.br/conteudo_view.asp?id $=344$

21. Pessoa JHL, Balikjan P, Frittella S, Nascimento R, Ribeiro L. Não-adesão à prescrição após atendimento em pronto-socorro pediátrico. Rev Paul Pediatr 1996; 14(2):73-77.

22. Bilenko N, Yehiel M, Inbar Y, Gazala E. The association betwen anemia in infants, and maternal knowledge and adherente to iron supplementation in southern Israel. Isr Med Assoc J 2007; 9(7):521-524.

23. Queiroz SS, Torres MAA. Anemia ferropriva na infância. J Ped. 2000; 76(Supl. 3):298-304.

24. Silva DG, Priore SE, Franceschini SCC. Fatores de risco para anemia em lactentes atendidos nos serviços públicos de saúde: a importância das práticas alimentares e da suplementação com ferro. J Ped 2007; 83(2):149-156.

Artigo apresentado em 04/09/2011

Aprovado em 20/11/2011

Versão final apresentada em 10/12/2011 